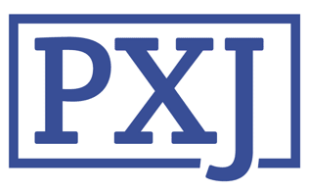

Patient Experience Journal

Volume 5 | Issue 3

Article 13

2018

\title{
The perioperative patient experience of hand and wrist surgical patients: An exploratory study using patient journey mapping
}

\author{
Else F. de Ridder \\ Delft University of Technology, Delft \\ Tessa Dekkers \\ Delft University of Technology, Delft \\ Jarry T. Porsius \\ Hand and Wrist Center, Xpert Clinic, the Netherlands / Erasmus MC, Rotterdam \\ Gerald Kraan \\ Reinier de Graaf Hospital, Delft \\ Marijke Melles \\ Delft University of Technology, Delft
}

Follow this and additional works at: https://pxjournal.org/journal

Part of the Industrial and Product Design Commons, Orthopedics Commons, and the Perioperative, Operating Room and Surgical Nursing Commons

\section{Recommended Citation}

de Ridder EF, Dekkers T, Porsius JT, Kraan G, Melles M. The perioperative patient experience of hand and wrist surgical patients: An exploratory study using patient journey mapping. Patient Experience Journal. 2018; 5(3):97-107. doi: 10.35680/2372-0247.1273.

This Research is brought to you for free and open access by Patient Experience Journal. It has been accepted for inclusion in Patient Experience Journal by an authorized editor of Patient Experience Journal. 
The perioperative patient experience of hand and wrist surgical patients: An exploratory study using patient journey mapping

\section{Cover Page Footnote}

The authors would like to thank all the participants and design researchers who made this project possible: the surgeons, OR staff, patients, and the 12 Industrial Design Engineering students from the elective Design of Products in Healthcare 2017 of Delft University of Technology. 


\title{
The perioperative patient experience of hand and wrist surgical patients: An exploratory study using patient journey mapping
}

Else F. de Ridder, Delft University of Technology, Faculty of Mechanical, Maritime and Materials Engineering, e.f.deridder@student.tudelft.nl

Tessa Dekkers*, Delft University of Technology, Faculty of Industrial Design Engineering, t.dekekers@tudelft.nl

Jarry T. Porsius, Hand and Wrist Center, Xpert Clinic, the Netherlands; Department of Plastic, Reconstructive and Hand Surgery,

Erasmus MC, Rotterdam, The Netherlands; Department of Rehabilitation Medicine, Erasmus MC, Rotterdam, The Netherlands,

j.porsius@erasmusmc.nl

Gerald Kraan, Reinier de Graaf Hospital, Department of Orthopaedic Surgery, kraang@rdgg.nl

Marijke Melles, Delft University of Technology, Faculty of Industrial Design Engineering,m.melles@tudelft.nl

*Corresponding author

\begin{abstract}
Patient-centred care is becoming more important in healthcare. The success of patient-centred care can be assessed by exploring the patient experience through a patient journey map. As the number of outpatient surgeries is increasing, it is important to reveal the specific characteristics of this type of surgery. The perioperative patient experience is considered very important for outpatient surgery, because all perioperative activities are condensed in one day. To investigate this experience, we performed a case study of hand and wrist surgery. Six teams of two industrial design engineering students interviewed 40 patients in total in two private and two public hospitals in the Netherlands. All teams created a patient journey map, describing the patient experience. These maps were analysed by the authors to identify common themes among the six journeys. Four time-independent themes and four time-dependent themes were identified. Insecurity, reassurance by staff, loneliness, and lack of information were associated with the whole patient experience. Before surgery, lack of control was the most prominent experience. During surgery, acceptance and curiosity were present. After surgery, relief was the dominant experience. No significant differences between the public and private hospitals were discovered. Several suggestions are given on how to facilitate positive experiences and how to resolve negative experiences in outpatient surgery. These include suggestions for hospital policy and design interventions.
\end{abstract}

\section{Keywords}

Orthopaedic surgery, outpatient surgery, patient experience, qualitative methods, design, public hospital, private hospital

\section{Introduction}

The importance of patient-centred care is becoming more and more apparent to researchers and clinicians, as well as to patients themselves ${ }^{1,2}$. Patient-centred care can be defined as care delivery specified to the needs and preferences of the patient ${ }^{3}$. Exploring the patient experience can assess the success of patient-centred care, and the results from such studies can be used to improve patient-centred care ${ }^{2,4}$.

One way to understand the patient experience is by researching the patient journey. A patient reported experience measure (PREM) questionnaire could be used to investigate the patient experience with respect to several factors, such as pain control, involvement, and communication ${ }^{1,5}$.
Investigating the patient experience has become an emerging research area over the past few years ${ }^{6}$. The importance of an optimal patient experience is shown by its relation to treatment outcomes. This includes functional capacity, mobility, and pain reduction ${ }^{7}$. Although there is no consensus on this subject ${ }^{8}$, there are numerous indications that clinical outcomes are positively influenced by a good patient experience $1,2,7,9$. For example, a positive patient experience improves the patient's adherence to medication and other care regimens prescribed by the physician ${ }^{2,7}$.

A positive patient experience is also an important factor when undergoing surgery, and is determined by all interactions that take place during the patient's contact with the healthcare system ${ }^{6}$. Numerous researchers have tried to determine factors that contribute to a positive patient experience. For example, Marshall et al. (2012) interviewed ten surgical patients, and concluded that 
contact with staff and the system in which healthcare is received contributed to the experience of the care they received ${ }^{10}$. Bleich and colleagues (2009) found that satisfaction with the healthcare system is significantly associated with a positive patient experience ${ }^{11}$. Black et al. (2014) included eight components of patient experience in their questionnaire and concluded that communication with and trust in doctors and nurses, and sufficient explanation and involvement were most strongly associated with treatment effectiveness. They also discovered a significant positive association between patient experience and this effectiveness ${ }^{1}$. Marshall et al. (2012) and Luxford et al. (2011) support the finding regarding the importance of interpersonal relationships, and conclude that patient and family engagement is an important player ${ }^{3,10}$. Kennedy et al. (2014) suggest that doctor's interpersonal skills are arguably the most important contributing factor to the patient experience ${ }^{12}$. Education and information was also found to be a significant factor in studies done by Björvell and Stieg (1991), Gilmartin (2004), and Rhodes et al. (2006) ${ }^{13-15}$. The importance of communication is also highlighted by the latter study. Doyle et al. (2013) associated patient safety and clinical effectiveness with patient experience ${ }^{7}$. Concluding, several aspects of care provision, including adequate communication, engagement, and information, are strongly related with an overall positive patient experience.

Most studies focused on the general patient experience of the whole continuum of care but did not focus specifically on one phase of the patient journey. Yet, one can distinguish three distinct phases within the continuum of care, which may result in different patient experiences. The preoperative phase contains all events from the moment the patient comes in contact with the health care system, until the day of the operation. Several consultations with the surgeon and anaesthesiologist, amongst others, take place during this phase ${ }^{16}$. The day of the operation itself is called the perioperative phase. The postoperative phase takes place after the surgery, and contains several events, like rehabilitation.

As the number of outpatient procedures is increasing, knowledge about this type of surgery specifically is required ${ }^{17}$. It is known that the perioperative experience plays a very important role for patients receiving day surgery ${ }^{18}$. Because all parts of the perioperative phase, such as hospital admission, surgery, and discharge happen on the same day, this phase is very intense ${ }^{18}$. It is expected that for outpatient surgery, the perioperative phase has its own challenges in terms of patient experience. For example, it is known that a higher prevalence of anxiety exists in the perioperative phase of outpatient surgeries 17,19 , which can result in unfavourable clinical outcomes 16,17 .
The current paper will explore the perioperative patient experience in an outpatient setting. To do so, we performed a case study of hand and wrist surgery. Hand and wrist surgery typically happens in a day surgery setting ${ }^{19}$, which means that the patient is discharged on the day of the surgery. Injuries to the hand or wrist can greatly impair the daily life activities of the patient. Surgery is one possible solution to restore the functionality of the hand and wrist. Because the perioperative patient experience of this type of surgery is not well understood, we aim to investigate the patient experiences on the day of the surgery just before, during, and after the surgery in the day surgery setting. We will identify themes that play a role in determining the patient experience. Identified positive and negative aspects of this phase can later be used to improve the perioperative patient experience, in order to maximize clinical outcomes. These insights will also lead to opportunities for improvements by design. It is expected that the themes discussed above will reflect as contributing factors to the patient experience in our results. The patient experiences will be documented by means of a patient journey map. This map can provide useful insights of the patient experience ${ }^{20}$.

In addition, we will address the perioperative patient experience in both public and private hospitals, to discover potential differences and similarities. It is known that several differences exist between public and private healthcare. For example, users of private health care are known to have better accessibility in obtaining short notice care, but public healthcare users are more satisfied in terms of access to healthcare service provision ${ }^{21}$. After analysing the World Health Survey 2003, Bleich and her colleagues concluded that satisfaction is lower among people receiving private healthcare, possibly because the patient's expectations were higher and private healthcare costs more 11. Because of these known differences, investigating the patient experience in both settings could lead to valuable insights.

\section{Design and Methods}

\section{Research design}

For this qualitative exploratory research, six teams of two industrial design engineering master students observed hand and wrist surgeries. Observations were made at one public hospital with two locations, and one private hospital with two locations in May and June 2017 in the Netherlands. All hospitals provided insured healthcare to its patients. Each team was linked to a surgeon, whose surgery practice was observed and with whom preliminary group insights were discussed. Three teams were linked to three different surgeons from the public hospital, and the other three teams were linked to two surgeons from the private hospital. One surgeon was coupled to two teams. 


\section{Methods}

The main method for identifying the perioperative patient experience was process mapping of the patient journey 22 . Patient journey mapping combines several methods "to see and understand the patient's experience by separating the management of a specific condition or treatment into a series of consecutive events or steps" ${ }^{22}$. Data was collected through direct observation and informal interviews with patients and staff by researchers who 'walk the journey' themselves or shadow patients during their journey in real time. The cumulative observation time of all six teams was approximately 36 hours. The method was further supplemented by multi-disciplinary meetings in which the representative staff discussed the patient journey with the students.

Data acquisition was either done via unstructured patient interviews before, during, or after surgery, or via observations, or a combination. Not every location allowed for the same combination of methods. When patients were interviewed, this happened in an informal manner, to ensure the patient was comfortable. The questions asked were general and open questions to minimize the influence of the questions on the patient's response. Examples of the questions are:

What factors influenced your experience here today? What events did and did not match your expectations? What would you improve about today if you could?

The interviews lasted 5 to 10 minutes, depending on the available time, state of the patient, and the willingness of the patient to participate. The patient's responses were documented afterwards, in order to have a natural conversation. Patient comfort was always the priority and interviews were stopped when the patient indicated not to be comfortable, or when it was observed that the patient was not comfortable.

Afterwards, these observations and interviews were combined into a patient journey map. Each team created one patient journey map with their observed patient experiences. One example of such a map is included for illustrative purposes of what the patient journey mapping method looks like (see Figure 1 at end of article). The patient journey starts at the point when the patient enters the hospital, and ends when the patient leaves the hospital, typically on the same day. The emotions of the patient were displayed graphically on the patient journey map to identify crucial moments during the perioperative experience. The students used the gained insights from the patient journey map to create improvements by design.

\section{Recruitment}

Before any observations were made or interviews were conducted, the surgeon informed the patient about participating in the research. Verbal consent of the patient was required before the team could make contact. Some patients declined to participate in the research for several personal reasons, like being too nervous or anxious.

Patients who underwent general anaesthesia were not able to discuss their experiences during or after the surgery and were excluded from this study.

\section{Patient sample}

All patients who provided verbal consent were included in this research. A convenience sample of approximately 40 patients was interviewed and observed during their perioperative experience. Patients undergoing various hand and wrist related surgeries were shadowed to obtain data ${ }^{23}$. Indications for surgery included, but were not limited to, metacarpal fractures, skier's thumb, and carpometacarpal (CMC) thumb arthritis. Patients from all genders and ages were included. About twice as many patients were interviewed in the private hospitals, as compared to the public hospitals, because more patients underwent surgery on the observation day.

\section{Analysis}

A thematic analysis was conducted in order to define patterns within the obtained data ${ }^{24}$. First, the student teams discussed the journeys with participating hospital staff and patients (when available) for validation ${ }^{25}$. Next, the researchers (EFdR, TD, MM) used these patient journey maps to discuss common themes over several meetings. Finally, these themes were presented to the hospital representatives (JTP, GK) for final inclusion.

\section{Results}

A generalised patient journey is described below, in order to give an impression of what the day looked like for a patient undergoing day surgery. After comparing all six patient journeys, eight themes were identified. Not all themes were identified by all student themes for every patient. The number of teams that identified the themes can be found in Table 1. These themes are listed below and are supported with patient quotes. The quotes were provided by the patients in Dutch and were translated to English by the student teams for use in their patient journeys. Four themes were identified that are present during the whole patient experience, i.e. these themes were time independent. The four remaining themes are time specific and are listed chronologically. Some experiences contributed to a positive and some to a negative patient experience. Most patients regarded hand and wrist surgery as a minor surgery and were not very anxious. 
Table 1. Summary of the identified themes

$\begin{array}{lll}\text { Themes } & \begin{array}{l}\text { Identified by } \\ \text { \# of teams } \\ \text { (out of } 6)\end{array} \quad \text { Description } & \end{array} \quad$ Patient quote

\begin{tabular}{|c|c|c|c|c|}
\hline \multirow{4}{*}{$\begin{array}{l}\text { Overall } \\
\text { perioperative } \\
\text { experience }\end{array}$} & Insecurity & 3 & $\begin{array}{l}\text { The patient feels insecure } \\
\text { because he or she does not } \\
\text { know what will happen exactly. }\end{array}$ & $\begin{array}{l}\text { I would like to ask the } \\
\text { nurse something, but she is } \\
\text { attending to another } \\
\text { patient. }\end{array}$ \\
\hline & $\begin{array}{l}\text { Reassurance } \\
\text { by staff }\end{array}$ & 4 & $\begin{array}{l}\text { Talking to the staff makes the } \\
\text { patient feel reassured when he } \\
\text { or she is anxious or wants to } \\
\text { know something. }\end{array}$ & $\begin{array}{l}\text { Chitchat with the staff } \\
\text { was the most comforting } \\
\text { aspect of the day. }\end{array}$ \\
\hline & Loneliness & 2 & $\begin{array}{l}\text { Because staff is not always } \\
\text { available, feelings of loneliness } \\
\text { arise. }\end{array}$ & $\begin{array}{c}\text { I had to wait very long by } \\
\text { myself before they took me } \\
\text { back to the nursing } \\
\text { department. }\end{array}$ \\
\hline & $\begin{array}{l}\text { Lack of } \\
\text { information }\end{array}$ & 2 & $\begin{array}{l}\text { Information is insufficient, and } \\
\text { information is not retained, } \\
\text { resulting in a lack of } \\
\text { information. }\end{array}$ & $\begin{array}{l}\text { I remember vaguely that } \\
\text { the anaesthesiologist told } \\
\text { me this, but I cannot } \\
\text { recall exactly what. }\end{array}$ \\
\hline Before surgery & $\begin{array}{l}\text { Lack of } \\
\text { control }\end{array}$ & 3 & $\begin{array}{l}\text { The patient has the feeling that } \\
\text { he or she is not in control of the } \\
\text { situation, because the patient } \\
\text { has to do what the nurse or } \\
\text { doctor tells him or her to do. }\end{array}$ & $\begin{array}{l}\text { Of course the doctor } \\
\text { knows best, but I know it } \\
\text { when I need or want } \\
\text { something. }\end{array}$ \\
\hline \multirow[b]{2}{*}{ During surgery } & Acceptance & 4 & $\begin{array}{l}\text { The patient realises the surgery } \\
\text { is happening and accepts this } \\
\text { fact. }\end{array}$ & $\begin{array}{l}\text { The surgery is a necessary } \\
\text { evil, but what has to be } \\
\text { done, has to be done. }\end{array}$ \\
\hline & Curiosity & 4 & $\begin{array}{l}\text { The patient becomes curious } \\
\text { and more relaxed, and wants to } \\
\text { know more or observe the } \\
\text { surgery. }\end{array}$ & $\begin{array}{l}\text { I would like to watch the } \\
\text { surgery and ask what the } \\
\text { surgeon is doing. }\end{array}$ \\
\hline After surgery & Relief & 5 & $\begin{array}{l}\text { The patient is relieved that the } \\
\text { surgery is over, and that he or } \\
\text { she is reunited with friends and } \\
\text { family and can go home. }\end{array}$ & $\begin{array}{l}\text { I'm glad the surgery is } \\
\text { over and that I can go } \\
\text { bome now. }\end{array}$ \\
\hline
\end{tabular}

\section{Patient journey}

Typically, the patient entered the hospital in the morning and was directed to the surgical department. There, the patient presented him- or herself at the front desk and is registered. The patient was taken to the nursing room where several nurses took care of a number of patients. After some time, the patient was transferred to the surgical complex. At the holding, the patient received the regional anaesthesia, and had to wait until the anaesthesia was fully working. The patient was transferred to the operating room (OR) where the patient met the surgeon, and, after a short time-out, the operation was performed. At the end of the surgery, most patients received a cast or splint. After the surgery, the patient was briefly admitted to the recovery room, until he or she was released by the nurse and transferred back to the nursing department. Here, the patient was offered something to eat and drink, and was reunited with friend or family, who took the patient home after discharge. This patient journey can also be found in Figure 1.

\section{Time-independent perioperative patient experiences}

Four themes were identified that were present continuously over the duration of the whole perioperative patient experience: insecurity, reassurance by the staff, loneliness, and lack of information.

\section{Insecurity}

Insecurity was the result of the patient not knowing exactly what will happen on the day of the surgery. As it was not 
always possible to ask someone (or patients feel it was not possible to ask someone), like a nurse, doctor or fellow patient, what is going to happen next, many patients described feelings of insecurity. The unfamiliar environment, such as the looks of the rooms and the surgical gowns the patient had to wear, reinforced this feeling. This feeling stayed present during the whole day.

"I would like to ask the nurse something, but she is in the other room attending to another patient."

However, patients indicated that the atmosphere was especially good in the waiting room of the private hospitals, because the rooms felt cosy and less like a hospital. This was explicitly indicated by patients receiving treatment in the private hospitals, and not by patients in the public hospitals. The patients indicated that this cosiness made them feel more comfortable. For example, the waiting rooms in the private hospitals looked more like a living room, with soft and comfortable chairs. On the other hand, the waiting rooms in the public hospitals were more functional, with several rows of wooden chairs. A patient from a private hospital stated:

"The waiting room does not feel like a hospital waiting room at all."

Patients from the private hospitals explicitly mentioned the feeling of insecurity regarding the surgical gowns. In the private hospitals, the patients were required to walk between the different departments, whereas in the public hospitals, the patients were transferred in their bed. This introduced feelings of insecurity to the patients in private hospitals. A patient from the private hospital expressed her experience as:

"I felt very watched by the other patients when I had to walk from the nursing department to the holding area."

Reassurance by staff

Another prominent experience throughout the whole perioperative phase was the reassurance felt by patients when they interacted with staff. Because numerous situations arose during the day for which the patient wanted to receive support and new information, this reassurance was desired during the whole day. Interestingly, patients were not only looking for practical information, but also an emotional connection with the staff.

"Chitchat with the staff about my daily life makes me feel more relaxed."

\section{Loneliness}

Finally, loneliness was also an emotion that was present throughout all stages within the perioperative experience. Because patients were not always able to interact, or felt unable to interact with the medical staff, some expressed to feel lonely throughout the day.

"I had to wait for a very long time by myself in the recovery room before they took me back to the nursing department."

\section{Lack of information}

Several patients indicated that they felt like not enough information about the planning and procedures was available. They did indicate that during the preadmission contact with the surgeon and anaesthesiologist information was provided about the surgery and anaesthesia, but most patients were unable to recall this information accurately. For example, patients and their families expressed that they did not know when surgery would take place or how long the surgery would take.

"I thought I would be helped right away, but I've been sitting here waiting for the last three hours."

The lack of information was most apparent when administering the anaesthesia. Patient indicated that they would have liked more information about this procedure, but that this was unavailable. The anaesthesia itself had a negative impact on the patient experience for a brief period of time, because unexpected bodily sensations caused a feeling of lack of control of the body. Most patients received a multiple injection axillary block but could request light sedation if they were very anxious.

"At some point I could not lift my arm any more. That
was very unexpected."

Furthermore, a lack of information about rehabilitation made the patient feel insecure. Patients expressed their interest in learning about the rehabilitation process right after the surgery, but this information was not available to the satisfaction of the patient.

"I would like to know how long I have to wear this cast, because I'd like to go back to work as quickly as possible"

\section{Time-dependent perioperative patient experiences}

Next to these emotions experienced throughout the day of surgery, several other experiences arose and decreased as the day progressed.

Lack of control

Before the surgery, a common theme was the feeling of lack of control. This feeling was also enforced by the lack of procedural and practical information. Altogether, it was observed that patients feel uncomfortable during this part of the perioperative phase.

Patients indicated that they had the feeling that they just had to do as they were told, fuelling the feeling that they 
were not in control of the situation. Patients further indicated that foreign environments (the different departments where the patient stayed), foreign clothing (the surgical gown), and foreign sensations (anaesthesia) attributed to the experience of lack of control. This feeling was mostly present before the surgery and decreased as the patient became more familiar with the new situations.

"The weird clothes give me an uncomfortable feeling."

One patient in the private setting indicated that she felt as if she was part of an industrial process, because so many quick surgeries were performed in one day. This made her feel as if she was not in control of the events happening. Patients in public hospitals did not indicate this. The number of patients interviewed per setting also shows this, with twice as many patients interviewed in the private hospitals as compared to the public hospitals.

\section{Acceptance}

The patient's feelings changed drastically when the patient was about to undergo the surgery. Patients indicated that they now acknowledged the necessity of the surgery to regain functionality of the hand and wrist, resulting in feelings of acceptance.

"I just want the surgery to be over, so I can start focusing on my recovery; I want to resume the activities that I enjoy doing."

As previously mentioned, anaesthesia resulted in unexpected bodily sensations. Yet, it was also observed that when patients grew accustomed to the sensations induced by the anaesthesia, the realisation that surgery was about to happen took over. This further reinforced acceptance and made the patient generally more relaxed.

\section{Curiosity}

In some cases, it was found that when patients accepted the approaching surgery and became more relaxed, they also became more curious and searched for opportunities to become more actively involved in the surgical process. For example, several patients wanted to watch the X-ray during the surgery to feel more engaged.

"At first, I was anxious and did not want to see anything, but after a while I became curious and wanted to watch the surgery."

\section{Relief}

After the surgery, feelings of relief were dominant for most patients. They realised in retrospect that the surgery was not as bad as they had expected. Patients indicated that if someone had told them this in advance, their anxiety would probably have been lower.
"I'm happy that it is over, but if someone told me everything was going to be OK, I would have been less anxious."

\section{Discussion}

The aim of this research was to gain insight in the perioperative patient experience of hand and wrist surgery patients. We set out to identify the emotional experiences belonging to patients receiving outpatient surgery. Six teams of two industrial design engineering master students observed hand and wrist surgeries to develop so called patient journey maps, which visualise the day of surgery from the patients' perspective. These maps were analysed in order to identify common themes among the patient experiences. We discovered that distinct emotions are present during the perioperative patient experience, which have policy and design implications.

In this discussion, the themes that were identified are compared with existing research, if possible. Two possible design directions to improve the patient experience are explained, based on the proposed designs by the student teams. Furthermore, suggestions about future research on this topic and some limitations of this research are listed.

Overall, it could be observed that the patient experience improved as the day of surgery progressed. Throughout the day, feelings of insecurity, reassurance by the staff, loneliness, and lack of information were present. When the patient entered the hospital, lack of control was the most prominent, but when the actual surgery drew closer, feelings of acceptance and curiosity took over. After the surgery, most patients experienced relief.

Although this study only looked at hand and wrist surgery patients in particular, it is expected that several identified themes would also be applicable to a broader range of outpatient surgeries. Future research is needed to identify which themes apply to a broader spectrum of outpatient surgeries.

The finding that contact with staff reassured patients is supported by earlier work. For example, surgical patients interviewed at least two days before discharge indicated that connectedness, involvement, and attentiveness of staff were important determinants of their patient experience ${ }^{10}$. This study is in line with our findings; patients felt reassured and more at ease when communicating with staff. The staff provided the patients with information they required, but small talk was also important to make the patient feel more comfortable. McCabe (2004) also researched this topic of communication, and concluded that patient-centred communication is essential, by involving the patient in decision making regarding their care ${ }^{26}$. Furthermore, Sheppard (1993) highlights the 
importance of communication about feelings, in addition to communication of information ${ }^{27}$.

Similarly to the loneliness expressed by patients in our study when there was limited contact with staff, Gilmartin and Wright (2008) discovered that abandonment by staff resulted in a negative patient experience in day surgery ${ }^{28}$. This highlights the importance of contact with staff for a positive patient experience. Hospital policy should include these findings as suggestions to the personnel to improve the patient experience.

In our research, patients indicated that lack of control contributed negatively to their perioperative experience. Because they did not know what to expect, just had to do as they were told, and because of the unfamiliar environment, this feeling was present. But this is not the only influence the environment can have on the patient experience. Marshall et al. (2012) also discovered that the physical environment, such as the food and bedding, contributed to a negative patient experience ${ }^{10}$. The researchers concluded that patients saw this factor as integral to a positive patient experience. These findings combined show what the influence of the physical environment can be on the patient experience, and the importance for the hospital to consider this.

Marshall et al. (2012) did not associate the environment directly with the feeling of lack of control. But what they did associate with lack of control, was the experience of patients that they just have to do as they are told ${ }^{10}$. The researchers described this as a power imbalance: the patient acknowledges that the doctor knows what's best for the patient, but this gives the patient the feeling that he or she cannot tell the doctor what he or she feels or desires. This specific power imbalance was not explicitly identified by our research but could be more elaborately researched in future work.

Reassurance by staff could be implemented in hospital policy to improve the patient experience; involvement of the patient makes the patient feel more included in the situation and more in control ${ }^{10}$. Communication between patient and staff, an important contributor to a positive patient experience according to Rhodes et al. (2006) and Black et al. (2014), could also help to decrease this feeling of lack of control ${ }^{1,15}$. Although not mentioned explicitly by the patients, it was observed that communication about procedural and practical information, but also informal small talk was desired. What aspects of communication are most important to improve the experience should be researched in future studies.

Lack of information is known to influence the patient experience negatively ${ }^{13-15}$. Not being informed can result in anxiety; this can be managed by providing adequate preadmission contact for patients and their families ${ }^{15}$. This is also known to improve perioperative outcomes ${ }^{15}$. Providing information during the hospitalisation is also known to influence the patient experience positively ${ }^{13}$. However, Wilcox and colleagues (2010) emphasize the fact that recollection of this information provided to the patient before or during their stay in the hospital is very poor ${ }^{9}$. Therefore, information should be made readily available during the stay in the hospital, to let the patient access the required information when he or she feels the necessity to do so.

The interviewed patients indicated explicitly that they wanted more information about certain aspects throughout the day, like procedural information about the anaesthesia administration. Fear for the regional anaesthesia is a well-researched subject ${ }^{29}$. KoscielniakNielsen and colleagues discovered that the anxiety for the anaesthetic procedure is reduced after step-by-step explanation.

Several patients also expressed their interest in learning about the rehabilitation process. The information provided by the surgeon after the surgery was considered unsatisfactory by some patients. This result is supported by the literature review performed by Costa (2001) ${ }^{18}$. She identified 'discharge readiness' as one of the most prominent problems that day surgery patients face during their perioperative experience. Making information, for example about the duration of the rehabilitation process or the duration the cast has to be worn, available directly after the surgery could therefore improve the patient experience.

From observations, it became clear that patients required information about procedures and planning. However, it was unclear what information could contribute the most to improve the patient experience. Future research should reveal what kind of information (e.g. procedural or planning) and in what form (e.g. verbal or written) is mostly desired.

It was observed that patients started to accept the surgery more as the moment of the actual surgery came closer. Feelings of acceptance had not been associated with the perioperative patient experience before. The current study found that the experience of acceptance generally arose just after the anaesthesia was applied. During their hospitalisation, patients overcame their anxiety because they became more familiar with the new environment and wanted the surgery to be over, so they could focus on regaining functionality of the hand and wrist. Because hand and wrist related injuries greatly impair the daily life activities of the patient, most patients indicated that they were looking forward to the surgery, so they could resume their normal activities afterwards. 
The results showed that some patients became curious during the surgery, after they accepted its necessity. The patients indicated that they wanted to be more involved in the procedure and sought opportunities to be more involved. It is important to facilitate this, because feelings of curiosity and participation are known to contribute to a better patient experience ${ }^{3}$.

Most patients were relieved after the surgery was over. They also indicated that the whole day was not as bad as they had expected it to be. It is therefore suggested that peer contact could have a positive impact on the patient experience. Exchanging experiences with fellow patients could help manage the patient's expectations better.

Trust in their doctor is considered to be one of the most associated factors with patient experience ${ }^{1}$, but this was not discovered during this research. It is possible that trust is not an issue in this situation, because it is something that is inherent when the patient decides to undergo the procedure at that specific hospital. Furthermore, it could be that patients did not mention this aspect because the researchers did not specifically ask for it.

\section{Comparison public and private}

No major differences in patient experience between public and private hospitals were detected. Both sectors had their own positive and negative experiences, but this did not result in a detectable difference. This result was also found by Pérotin et al., who researched the patient experience in public and private hospitals in England ${ }^{30}$. This could be due to the fact that patients underwent the same types of surgeries in both settings. Patients considered hand and wrist surgery as a minor surgery, and generally had a relaxed attitude towards the procedure. Because patients in both private and public hospitals had the same attitude towards the operation, the differences between the two settings were not revealed. It might be possible to reveal this when the surgery is more severe for the patient. Also, because hand wrist patients are only admitted for one day and generally go home directly after the surgery, their patient experience was not long enough to detect any differences between the private and public sector.

One patient from a private hospital indicated that she felt part of an industrial process. No patient from the public setting indicated this. This could be due to the fact that about twice as many patients underwent surgery in the private hospitals than in the public hospitals on the days of the observations. To our knowledge, this feeling has not been recorded before. Even though only one patient indicated this, future research should find out whether this feeling is present for more patients.

If it is aimed to reveal differences between private and public hospitals, the study design should facilitate this. For example, patients who underwent surgery in both private and public hospitals should be observed and interviewed in order to draw meaningful conclusions regarding this comparison.

\section{Design directions}

The six student teams proposed several interventions. These solutions can be roughly divided into two categories.

The first category contains solutions that aim to improve the overall perioperative patient experience. These designs focused on supporting the patient throughout the day of surgery. An example of such a design is a digital platform to provide the patient with information about the multiple procedures and situations that take place on the day of the surgery. This information is communicated by short videos that can be accessed via the hospital's website or an app. The patient can choose when to access the videos: beforehand at home, or during the hospitalization. During the first evaluation of the concept in the hospital, it became clear that it is essential that every patient can adjust the amount of information to accommodate the patient's needs. Nevertheless, the overall reaction to the concept was that it would provide a feeling of control and adequate information that is not available to patients by other means.

The second category targets one specific moment or experience during the perioperative period. One example of such a design facilitated the participation and curiosity of the patient during surgery. The design team suggested using the sterile surgical cloth that secludes the patient from the rest of the OR. The set-up with the cloth is essential from a hygiene perspective, but currently does not facilitate participation and curiosity. Therefore, the suggested re-design included a cloth support arch and smart light. The arch would create an open space around the patient's face, without breaking the sterile barrier. The envisioned function of the smart light was that by pressing a button to turn on the light, a patient would be able to draw the attention of the OR personnel to ask questions. It is expected that such a solution will make the patient feel more engaged and included in the OR.

\section{Strengths and limitations}

A major limitation of this research is that the most anxious patients, who could provide valuable insights about the patient experience, were not included. This was because they indicated that they did not want to participate because of this anxiety, or because they were not able to communicate during and after the surgery because of the light sedation they requested. As not to interfere with these vulnerable patients, no further questions about this anxiety were asked. It is suggested that for future research, these patients are included as well. This can be achieved by conducting an interview several days after the surgery, to record their experience in retrospect. 
Furthermore, every team was free to formulate their own interview questions and to conduct unstructured, informal interviews in a way that they considered appropriate for the situation. Every team had the same aim and overarching methodology, but their results could vary because of different executions of this research method. This could be seen as a strength of this research method, because it is likely that more themes were discovered in this way. However, not all teams found the same themes, which can either be because some themes were not present in all settings, or be a result of this research method.

Lastly, the research method had its limitations. Because the interference with the patient on the day of the surgery was kept as low as possible, no personal data like age and gender was recorded. Therefore, it is possible that this method resulted in a misrepresentation of the population.

\section{Future research}

The aim of this research was to identify themes that contribute to the perioperative experience of hand and wrist surgical patients. In addition to the previously mentioned suggestions for future research, we would like to point out three more directions.

Conducting the same research in both private and public hospitals generated a more complete overview of the contributing factors to the perioperative patient experience. However, this also resulted in a small sample size for both the private and public settings. Therefore, we were not able to directly compare the patient experience between public and private hospitals. It is therefore recommended that more hospitals, both private and public, should be included in future research to investigate whether differences between such hospitals exist.

Nowadays, the patient experience is becoming a more popular research subject. However, the experience of other stakeholders within the medical system, like nurses or surgeons, was not included in this research. Because communication between the patient and other actors is also important for the patient experience ${ }^{1,31}$, it is recommended that researching their experience could provide a more holistic insight in how the patient experience can be improved.

Furthermore, it should be more extensively researched how the perioperative patient experience relates to clinical outcomes. Because no consensus exists regarding this relation ${ }^{8}$, researching the influence of the identified contributing factors could provide useful insights regarding this relationship. This could facilitate the improvement of the patient experience and clinical outcomes simultaneously.

\section{Conclusion}

The aim of this exploratory study was to identify themes that are common for the perioperative patient experience of hand and wrist surgical patients. Eight such themes were discovered, some contributing to a positive, and some to a negative patient experience. Four themes were found to be time-independent, e.g. to be present throughout the whole perioperative experience. The four remaining themes were found to be specific for a particular moment of the day. Although a case study of only hand and wrist surgical patients was performed, it is expected that some themes could be applicable to other outpatient surgeries as well. The findings can be implemented in hospital policy or translated to design solutions in order to improve the patient experience.

\section{References}

1. Black N, Varaganum M, Hutchings A. Relationship between patient reported experience (PREMs) and patient reported outcomes (PROMs) in elective surgery. BMJ Qual Saf. 2014;(23):534-542. doi:10.1136/bmjqs-2013-002707

2. Browne K, Roseman D, Shaller D, Edgman-Levitan S. ANALYSIS \& COMMENTARY Measuring Patient Experience As A Strategy For Improving Primary Care. Health Aff (Millwood). 2010;29(5):921925. doi:10.1377/hlthaff.2010.0238

3. Luxford K, Safran DG, Delbanco T. Promoting patient-centered care: a qualitative study of facilitators and barriers in healthcare organizations with a reputation for improving the patient experience. Int J Qual Health Care. 2011;23(5):510-515. doi:10.1093/intqhe/mzr024

4. Elliott MN, Lehrman WG, Goldstein EH, et al. Hospital Survey Shows Improvements In Patient Experience. Health Aff (Millwood). 2010;29(11):20612067. doi:10.1377/hlthaff.2009.0876

5. Dawson J, Doll H, Fitzpatrick R, Jenkinson C, Carr AJ. The routine use of patient reported outcome measures in healthcare settings. BMJ. 2010;340(jan18 1):c186-c186. doi:10.1136/bmj.c186

6. Wolf JA, Niederhauser V, Marshburn D, Lavela SL. Defining patient experience. Patient Exp J. 2014;1(1):7-19.

7. Doyle C, Lennox L, Bell D. A systematic review of evidence on the links between patient experience and clinical safety and effectiveness. BMJ Open. 2013;3(1):1-18. doi:10.1136/bmjopen-2012-001570

8. Manary MP, Boulding W, Staelin R, Glickman SW. The Patient Experience and Health Outcomes. N Engl J Med. 2013;368(3):201-203. doi:10.1056/NEJMp1213134

9. Wilcox L, Morris D, Tan D, Gatewood J. Designing patient-centric information displays for hospitals. In: 
ACM Press; 2010:2123.

doi:10.1145/1753326.1753650

10. Marshall A, Kitson A, Zeitz K. Patients' views of patient-centred care: a phenomenological case study in one surgical unit. J Adv Nurs. 2012;68(12):26642673. doi:10.1111/j.1365-2648.2012.05965.x

11. Bleich S, Özaltin E, Murray CJ. How does satisfaction with the health-care system relate to patient experience? Bull World Health Organ. 2009;87(4):271-278. doi:10.2471/BLT.07.050401

12. Kennedy DM, Fasolino JP, Gullen DJ. Improving the patient experience through provider communication skills building. Patient Exp J. 2014;1(1):56-60.

13. Björvell H, Stieg J. Patients' perceptions of the health care received in an emergency department. Ann Emerg Med. 1991;20(7):734-738.

14. Gilmartin J. Day surgery: patients' perceptions of a nurse-led preadmission clinic. J Clin Nurs. 2004;13(2):243-250.

15. Rhodes L, Miles G, Pearson A. Patient subjective experience and satisfaction during the perioperative period in the day surgery setting: A systematic review. Int J Nurs Pract. 2006;12(4):178-192. doi:10.1111/j.1440-172X.2006.00575.x

16. Ortiz J, Wang S, Elayda MA, Tolpin DA. Preoperative patient education: can we improve satisfaction and reduce anxiety? Braz J Anesthesiol Engl Ed. 2015;65(1):7-13. doi:10.1016/j.bjane.2013.07.009

17. Cooke M, Chaboyer W, Schluter P, Hiratos M. The effect of music on preoperative anxiety in day surgery. J Adv Nurs. 2005;52(1):47-55.

18. Costa MJ. The Lived Perioperative Patient Experience of Ambulatory Surgery Patients. AORN J. 2001;74(6):874-881.

19. Timmins F, McCabe C. Day Surgery: Contemporary Approaches to Nursing Care. John Wiley \& Sons; 2008.

20. Manchaiah VK, Stephens D, Andersson G, Rönnberg J, Lunner T. Use of the 'patient journey' model in the internet-based pre-fitting counseling of a person with hearing disability: study protocol for a randomized controlled trial. Trials. 2013;14(1):25. doi:10.1186/1745-6215-14-25

21. Owusu-Frimpong N, Nwankwo S, Dason B. Measuring service quality and patient satisfaction with access to public and private healthcare delivery. Int J Public Sect Manag. 2010;23(3):203-220. doi:10.1108/09513551011032455

22. Trebble TM, Hansi N, Hydes T, Smith MA, Baker M. Process mapping the patient journey: an introduction. BMJ. 2010;341(aug13 1):c4078-c4078. doi:10.1136/bmj.c4078

23. Chung KC. Hand and Wrist Surgery. Elsevier Health Sciences; 2012.
24. Braun V, Clarke V. Using thematic analysis in psychology. Qual Res Psychol. 2006;3(2):77-101. doi:10.1191/1478088706qp063oa

25. Mays N, Pope C. Qualitative research: Observational methods in health care settings. BMJ. 1995;311(6998):182-184. doi:http://dx.doi.org/10.1136/bmj.311.6997.109

26. McCabe C. Nurse-patient communication: an exploration of patients' experiences. J Clin Nurs. 2004;13(1):41-49.

27. Sheppard M. Client satisfaction, extended intervention and interpersonal skills in community mental health. J Adv Nurs. 1993;18(2):246-259. doi:10.1046/j.1365-2648.1993.18020246.x

28. Gilmartin J, Wright K. Day surgery: patients' felt abandoned during the preoperative wait. J Clin Nurs. 2008;17(18):2418-2425. doi:10.1111/j.13652702.2008.02374.x

29. Koscielniak-Nielsen ZJ, Rotbøll-Nielsen P, Rassmussen H. Patients' experiences with multiple stimulation axillary block for fast-track ambulatory hand surgery. Acta Anaesthesiol Scand. 2002;46(7):789-793.

30. Pérotin V, Zamora B, Reeves R, Bartlett W, Allen P. Does hospital ownership affect patient experience? An investigation into public-private sector differences in England. J Health Econ. 2013;32(3):633-646. doi: 10.1016/j.jhealeco.2013.03.003

31. Tongue JR, Epps HR, Forese LL. Communication skills for patient-centered care: research-based, easily learned techniques for medical interviews that benefit orthopaedic surgeons and their patients. JBJS. 2005;87(3):652-658 
Figure 1. Patient Journey Map

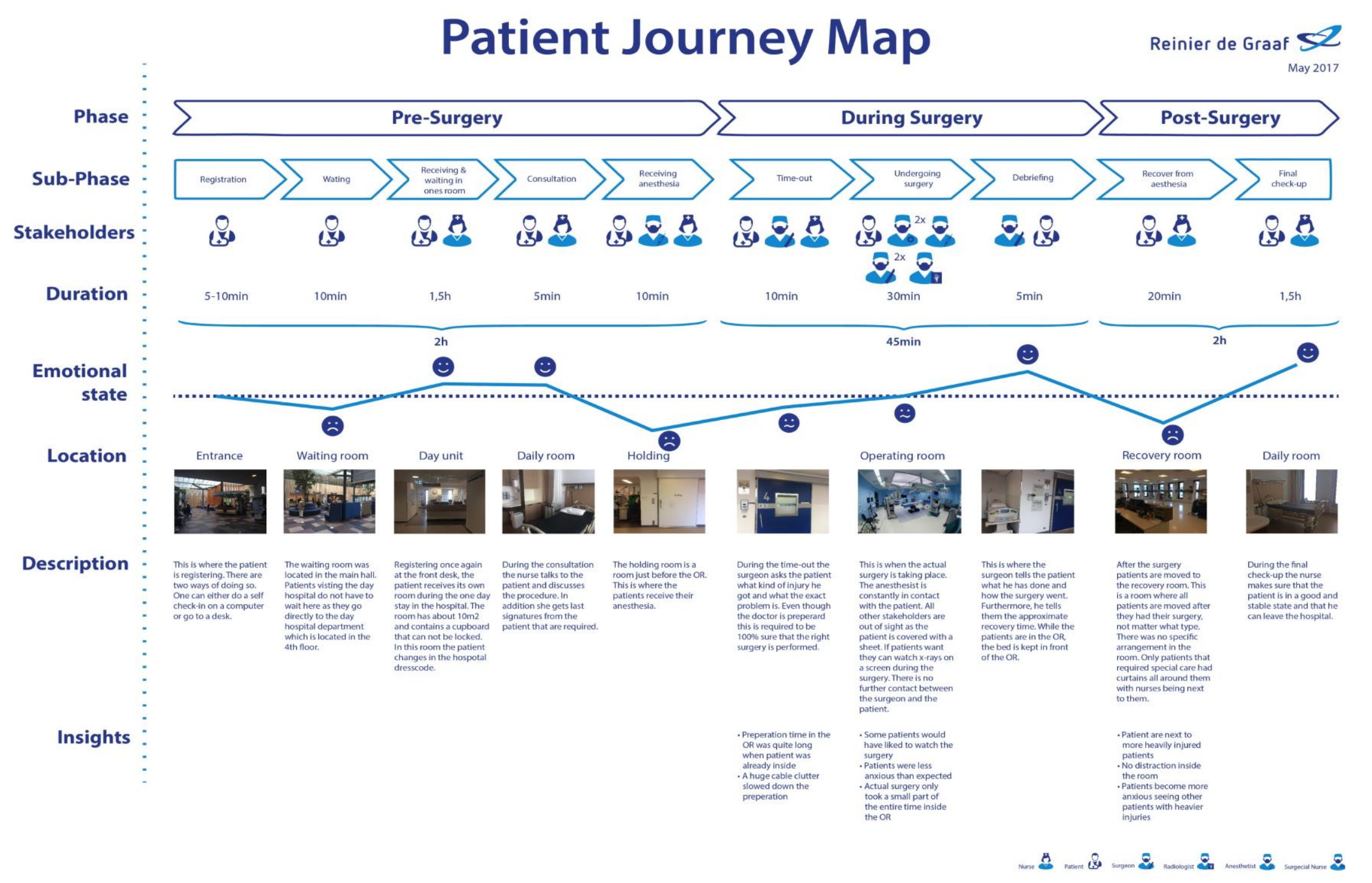

